\title{
Psychological Experience Dynamics of Students with Glossophobia through Narrative Counseling as seen from Gender: A Qualitative Study
}

\author{
Ajeng Intan Nur Rahmawati, Imam Ariffudin \& Mulawarman Mulawarman \\ Universitas Negeri Semarang, Central Java, Indonesia \\ intan.kons@gmail.com
}

\begin{abstract}
Psychological experience can lead to the fear of speech anxiety (glossophobia). A number of studies explain that 75\% people in the world have suffered glossophobia. The studies also revealed that, compared with men, women have higher tendency to experience glossophobia. The aim of the present study was investigating psychological experience dynamics and the role of gender that influence the emergence of glossophobia through narrative counseling. The data were collected qualitatively through observation and depth interview on five students of Public Senior High School 13 Surabaya. Furthermore, the data were analyzed thematically on three components of psychological experience dynamics: fear, anxiety, and negative thinking. The results of the analysis showed that most of the students are afraid to be laughed and humiliated. They are also anxious of past bad experience that would be repeated when speaking in public place. Moreover, excessive affection and cognitive responses of the female students are the trigger of experiencing glossophobia. Based on the interpretation, it can be concluded that misinterpretation of psychological experience and low-self-control of the students are able to determine glossophobia easily.
\end{abstract}

Keywords: Psychological experience dynamics, glossophobia, narrative counseling, and gender.

\section{INTRODUCTION}

Public speaking is an ability that can be an asset for an individual's life, including for students. Through the experience of public speaking, students are able to do various activities such as academic presentation and leadership in a community (Siliman, 2009). Ideally, every student can afford to do public speaking, but in fact public speaking is not that easy (Anholt, 2006). For example, LAH, one of the students in public senior high school in Surabaya, was experienced a fear and anxiety during public speaking and discussion. She became passive when encountering group work situation and presentation in front of class. Physical symptoms experienced by LAH involved cold sweat and stood frozen like ice when she was asked to come forward and presented something. She became embarrassed and she thought that her male friends will laugh at her, so the words that came out from her mouth were not smooth. Another student, AHS, also has similar experience when speaking in public place. When he was speaking in front of the class, he thought that his friends would disgrace him. Therefore, he felt that he looks foolish and become burlesque. The condition triggered the emergence of physical symptoms such as sweating, cold hands, and blurred eyes. The situation happened because AHS previously experienced an embarrassing situation in the public speaking.

The aforementioned physical and psychological symptoms show the informant has a tendency to become a glossophobian. According to APA (2013), glossophobia is the forms of social anxiety disorder (SAD). The patients have tendencies to avoid from public exposure (because the probability to be insulted and humiliated in public), anxiety, stress full, and also other autonomic symptoms such as tremor, tachycardia and other psychological problems. The symptoms can be an obstacle for self-development of the patients. Swenson (2011) adds data that $75 \%$ individuals have experienced glossophobia and most of them experienced by students. A number of studies show that woman tend to be more easily exposed glossophobia (Collbeck, 2011; Coburn, 2014; Khan, et al, 2015).

The phenomenon of glossophobia can inhibit the development of students. One effort to reduce the tendency level of glossophobia is through counseling. Counseling that used to reveal the dynamics psychological of glossophobia patients is the narration of life experiences. It is important for patients to reduce the burden of life caused by a traumatic experience in the past. One of the counseling that refer to the narration of life experiences is counseling narrative. Narrative counseling aims to construct the story of traumatic experience in the past to be a new story which focusing on the healing process (Capuzzi \& Stauffer, 2016; McLeod and Balamoutsou, 2007; Goncalves et al, 2009; McLeod, 2007). Moreover, narrative counseling can be used to decrease fear, shame, negative impression and interpretation, social inhabitation, and withdrawal (Loyeh et al, 2014). According to narrative counseling concepts, the situations are able to become a problem, because individuals tend to internalize the traumatic stories and make it as a part of life. Narrative counseling is very useful to fix the problem that affect individual.

The present research aims to explore, reveal, and understand the dynamic of psychological experience of the students who have glossophobia tendency through narrative counseling and as seen from gander. By understanding the dynamics of psychological experience in the perspective of gender, psychologist can give follow up in a preventive and curative manner. 


\section{METHOD}

The present research uses qualitative approach with phenomenological design. The design focuses on efforts to identify, explain, and describe the meaning of student's life experience related with glossophobia phenomenon. The informants who are selected by using purposive technique with typical case sampling are five students with glossophobia. They are received narrative counseling as many as 16 sections for each student during 6 months with the duration of 45 minutes per section (Lester, 1999; Creswell, 2015; Gorichanaz, 2017). Table 1 below explains the general demographic data of the informants.

Table 1. The Demographic Data of the Informants

\begin{tabular}{cccll}
\hline $\begin{array}{c}\text { Infor } \\
\text { mant }\end{array}$ & Gender & Age & Status & $\begin{array}{c}\text { Overall } \\
\text { Experience }\end{array}$ \\
\hline 1 & Female & 17 & Student & Positive \\
2 & Female & 17 & Student & Positive \\
3 & Female & 17 & Student & Positive \\
4 & Male & 17 & Student & Positive \\
5 & Male & 17 & Student & Positive \\
\hline
\end{tabular}

The data are collected by using open-ended interviews which are then transcribed in verbatim form.

Table 2. The Result of Thematic Analysis

\begin{tabular}{|c|c|c|}
\hline Main Theme & Sub Theme & Coding \\
\hline Anxiety & $\begin{array}{l}\text { Traumatic } \\
\text { event }\end{array}$ & $\begin{array}{l}\text { Repeated of bad } \\
\text { experience. } \\
\text { Not preparing the material. } \\
\text { Seen the opposite sex. } \\
\text { Psychosomatic (Sweating, } \\
\text { tremor, shacking, looking } \\
\text { down) Sculpting. }\end{array}$ \\
\hline Fear & $\begin{array}{l}\text { Being laughed } \\
\text { Being } \\
\text { shammed }\end{array}$ & $\begin{array}{l}\text { Being foolish. } \\
\text { Bad performance. } \\
\text { False of speech material. } \\
\text { Can't answering the } \\
\text { questions. }\end{array}$ \\
\hline $\begin{array}{l}\text { Negative } \\
\text { Thinking }\end{array}$ & Prejudice & $\begin{array}{l}\text { Negative feedback from } \\
\text { audience. } \\
\text { Labeling (secara personal } \\
\text { pada audience-nya) } \\
\text { Low ability. }\end{array}$ \\
\hline
\end{tabular}

Open-ended interviews are chosen due to the informants are able to express the experiences without being limited by research perspective or the finding of previous researches (Vasquez, 2000; Shoai, 2014; Creswell, 2015). Moreover, this research also uses open-ended observation (Creswell, 2015). The observation is conducted in a structured pattern in which the interviewer has determined the themes to be observed, such as mimic exchange, gesture, and voice intonation during narrative counseling process.

The results of data collection then were analyzed by using thematic analysis technique. Thematic analysis is a method for identifying, analyzing, and reporting patterns (themes) that aims to find central aspect within the data set (Braun \& Clarke, 2006). Thematic analysis' process is started from transcribing the result of interviews in to verbatim to make the researchers familiar with the data. Then, the researchers read them carefully to get the general idea of the theme that exists in the overall data. The researchers, further, split the general idea into main theme and sub-theme. Moreover, the data were coded and grouped in the same theme which has determined before (Braun \& Clarke, 2006; Howitt, 2010).

The validity of the data is measured through credibility, transferability, dependability, and conformability by using triangulation technique of data resource (Creswell, 2015). This technique is conducted by comparing and checking several resources, for example the interpretation of thematic analysis, with the result of data collection and exists theories. The conformity between all data resources can be used as a validation basis of the research result.

\section{RESULT}

As described in Table 2, the analysis is conducted on three main themes: anxiety with subthemes traumatic events and physical symptoms; fear with subthemes being laughed and being shammed; and negativethoughts with sub theme prejudice.

\section{Anxiety}

One of the facts experienced in people with glossophobia is anxiety. Anxiety becomes inseparable from the five informants when speaking in public area. This anxiety is experienced in both pre-action and postaction.

\section{Traumatic event}

Feeling anxiety experienced by glossophobian can bring up physical symptoms such as drooping, nervous, and even silent without saying a word. According to the informants, the situation is happened because they have experienced a bad experience when speaking in public so that they are worry the experience will be repeated. The anxiety experienced by the informants are diverse and sometimes irrational. They are feeling anxious if the audience is looking intently at them as if the audience's gaze is a judgment. Most of the students with glossphobia have experienced the dynamics of unpleasant experiences that must be memorable in their memories. As the result, they bring the experience to the future. Not onlylimited to bad experiences, it is certainly accompanied by the dynamics of emotion. The informants claimed that they did recognize the shadow of past experience as a predictor when they spoke in public, as if they turn back to the situation in the past. They also acknowledge that it is not easy to eliminate anxiety in public speaking, they need for mentoring and guiding.

The interviews quotes are as follows:

"I did not like to speak in front of the class since it was said that I am arrogant when I stepped forward and delivered a few things in front of the class. Another thing that makes me lazy to speak in public is when other people underestimate my answer".

[Informant 1]

"When I came to the front of the class and answered my friends' questions, they disgraced and dropped me as if I was a stupid person in front of the class. I am ashamed and silent".

[Informant 2] 
"In addition, other causes of bad experience are worse preparation and feeling anxious when viewed by the opposite gender. This is what makes them feel anxious and that anxiety will repeat the bad experience. See the following results of interviews".

"I was very nervous when I did not prepare the material well. This situation kept me silent and I did not answer anything. It is really bad". [Informant 5]

"I felt anxious and embarrassed when my male friends saw me in front of the class. It was like I was being looked at sharply with them".

[Informant 1]

\section{Physical Symptoms}

Students with glossophobia have both psychological and physical symptoms. Psychological symptoms include stress, panic, and soon, while physical symptoms are such as body vibrates, ducked, silent statues, blurred eyes, wringing hands, abdominal pain, or even pee in the pants. The informants had experienced all of these symptoms and they thought those situations were embarrassing and disgraceful experiences. As the result, they may not want to repeat the embarrassing moments. They also feel depressed because trying to eliminate the anxiety of being disgraced when speaking in public place. See the interview quotes below.

"I still remember, miss, when I came to the front of the class, I was so nervous and anxious. I squeezed my hands and my book. I suddenly felt stomachache"

[Informant 4]

"When I was appointed by my teacher to come in front of the class to answer her questions, my eyes were slightly blur and I was sweating until my back shirt and arms were wet"

[Informant 3]

\section{Fear}

Glossophobia is a mixture between feeling of anxiety and fear. People in this condition often experience both things simultaneously and feel unable to overcome them. The following informants are afraid to be laughed and humiliated. The two informants are afraid in expressing their opinion during the interview process. They argue that being laughed and humiliated is bad thing, so they thought that everyone who speaks in front of the class must be a perfect person without any mistake. During the counseling process, the dynamics of experience that often arise are about their fears and the emotions that accompany them. Some causes that make them feel anxious are less or imperfect appearance, unable to answer audience questions, afraid of being looked stupid and do not acquire the material, and afraid if the material that is presented is not appropriate with the interests and expectations of the audience. See the following interview quotes.

"Speaking in front of the class is a thing which makes me afraid. I am afraid if my performance was bad and slip".

\section{[Informant 3]}

"I thought that the most frightening thing when I am in front of the class is being humiliated. I could not answer my friends' questions and that condition makes me feel stupid and very embarrassed"

[Informant 2]

\section{Negative Thinking}

The activities which are done with the accompaniance of negative thoughts are not good because what will happen depends on what a person thinks. Similarly, students with glossophobia often think negatively (anxious) before speaking in public place. They are worry too much with their appearances. One of the things that the informants are not aware of is prejudice, either for themselves or others. The following are some prejudices such as negative feedback of audience, labeling the audience, and negative prejudice to self-ability.

Students with glossophobia often hold negative thoughts about the response of the audience when they are speaking in public place. Before they speak, they think that the response of the audience is not enthusiastic so that they are fixated on their own thoughts. As the result, their appearance is limited by their own negative thinking. During the counseling process, the informants acknowledge that they often think nonsensically before speaking. Below are the results of interviews.

"When explaining in front of the class, I am being intimidated by my friends. They always say that my words and explanations do not make sense"

[Informant 1]

"I'm sure my friends will ask me questions that I cannot answer because they only intend to make me look stupid in front of the teacher"

[Informant 2]

The emergence of labeling on the individual becomes one of the factors supporting glossophobia. The informants said that they would be more anxious and afraid when they saw one (or more) of the audience try to disturb them when speaking. They think that from the beginning someone will ruin the situation. See the following interview result.

"When there is "Mr. x", then he would break my concentration, I forget the material that I memorized. He is very annoying"

[Informant 4]

The next sub-theme is about self-acceptance. Most informants are not confident to their abilities to speak in front of audience so that they think and believe they are not able to do it. The informants are easier to say "no" than "try". They do not know much about the hidden potentials that can be used to avoid glossophobia. Following are the results of interview during the counseling process:

"I'm sorry, I do not think I can speak in front of people. I cannot handle my audience so that they are feeling bored (krik-krik)"

[Informant 2]

"I have done and tried many times, but I still feel afraid and stutter when I am speaking in front of the class. This is annoying"

\section{[Informant 5]}

"It may be true what my friends said that I am not an expert in group discussions. I suck in expressing my opinion"

[Informant 5] 


\section{CONCLUSION}

The present research is focused on exploring, exposing, and understanding the dynamics of the psychical experience: anxiety, fear, and negative thought as some feelings that experience by students with glossophobia. The result of this research is consistent with the explanation from Kushner (2004) that there are some physical and psychological symptoms felt by glossophobic patients; sweating, low blood pressure, irregular breathing, tremors, panic, anxiety, stress, and significant emotional changes.

In addition to the three main components, there are other components that can also trigger the tendency of glossopohobia such as the number of audience, the familiarity with audience, and the performance with team. The emergence of these other components is in accordance with the explanation from Pribyl et al. (2001); Heuet, \& Heuet (2011) that glossophobia can be influenced by several things: novelty, unfamiliarity, formality, subordinate status, quantity of audience, and quantity of group.

The appearance of all components is inseparable due to the influence of past experience, especially traumatic. Individuals who often experienced a traumatic life story will clutch the pain without being able to externalize it. This is proven by Johnson \& Anderson (2014) that people with glossophobia tend to be influenced by misinterpretation of their life experiences in traumatic situations. Referring to the above explanation, one of the counseling that focuses on the internalization of problematic in the past is narrative counseling. Corey (2015) and Cappuzi \& Stauffer (2016) support the above statement that narrative counseling focuses on the process of externalizing problems in the past by using story alignment and convince that the past bad experience is not a burden for the future.

Another topic of discussion in the present research is about gender perspective. The difference of gender (men and women) can lead to glossophobia differently. In fact, during the process of counseling, the women informants showed excessive attitude when responding to bad and shame situations than men. It is similar with an explanation given by Collbeck (2011); Coburn, (2014); Khan et al. (2015)who state that women tend to be more easily anxious and worry about the judgment of other people. Therefore, it is concluded that they are easier to suffer glossophobia. In addition, women are also easier to judge the audience so that their negative thinking would be raised. The loss of self-control of each individual lead to the emergence of anxiety in public speaking (Schultz \& Heimberg, 2008). Zell, Warriner, \& Albarracin (2012)state that self-control has correlation with the response showed by individual when they are speaking in public place through their body language.

Based on the results of the data interpretation, it can be concluded that anxiety, fear, and negative thought are the elements of dynamics of psychological experience possessed by students with a tendency of glossophobia. The tendency of glossophobia is caused by misinterpretation of the students' traumatic experience. In addition, the low self-control of the women makes them easy to experience glossophobia. Another research finding also showed that local cultural values greatly affects the students in responding to an event. Therefore, further researches are suggested to incorporate the cultural element as the variable that trigger the emergence of glossophobia.

\section{REFERENCES}

American Psychiatric Association. (2013). Diagnostic and Statistical Manual of Mental Disorder: DSM-5.- $5^{\text {th }}$ Edition. Arlington, VA: American Psychiatric Association.

Anholt, Robert R. H. (2006). Dazzle 'Em with Style: The Art of Oral Scientific Presentation $2^{\text {nd }}$ Edition. London, UK: Elsevier Inc.

Braun, V., \& Clarke, V., 2006. Using Thematic Analysis in Psychology. Qualitative Research in Psychology, 3(2), 77-101.

Capuzzi, David \& Stauffer, Mark D. (2016). Counseling and Psychotherapy Theories and Interventions. Alexandria, VA: American Counseling Association.

Coburn, A Heater. 2014. "Doing Gender" in Public Speaking Education: A Focus Group Analysis of Biological Sex and Gender Identity in Public Speaking Education. Journal of Undergraduate Research, 12(8), 37-41

Collbeck, J Jessica. (2011). The Impact of a Fundamentals of Speech Course on Public Speaking Anxiety. Journal of Undergraduate Research, 9(19), 145-160.

Creswell, John. (2015). Research Design: Qualitative, Quantitative, and Mixed Methods Research $5^{\text {th }}$ Edition. London: Pearson Education, Inc.

Goncalves, Miguel M., Matos, Marlene., \& Santos, Anita. (2009). Narrative Therapy and the Nature of "Innovative Moments" in the Construction of Change.Journal of $\begin{array}{lll}\text { Constructivist Psychology, 22(1), } & 1-23 .\end{array}$ http://dx.doi.org/10.1080/ 10720530802500748

Gorichanaz, Tim. (2017). Auto-Hermeneutics: A Phenomenological Approach to Information Experience. Library and Information Science Research, 39(1): 1-7. https://doi.org/10.1016/j.lisr.2017.01.001

Heuet, L Brian \& Heuet, B Kyle. (2011). Virtual Reality Therapy: A Means of Reducing Public Speaking Anxiety. International Journal of Humanities and Social Science, 1(6).

Howitt, Dennis. (2010). Introduction to Qualitative Methods in Psychology. England: Pearson Education Limited.

Johnson, Suzanne B \& Anderson, Page L. (2014). Stereotype Confirmation Concern and Fear of Negative Evaluation among African-American and Caucasian with Social Anxiety Disorder. Journal of Anxiety Disorder, 28(4) 390-393

Khan, Fahad., Sarosh, Ismail., Shafique, Muhammad Saqib., Ghous, Kulsoom., Ali, Syed Arif. (2015). Glossophobia among Undergraduate Students of Government Medical Colleges in Karachi. International Journal of Research(IJR), 2(1), 36-42

Kushner, Malcolm. (2004). Public Speaking for Dummies $\left(2^{\text {nd }}\right.$ $E d)$. Indianapolis, Indiana: Wiley Publishing, Inc.

Lester, Stan. (1999). An Introduction to Phenomenological Research. Retrieved from http://www.rgs.org/nr/rdonlyres/f50603e0-41af-4b159c84-ba7e4de8cb4f/0/seaweed phenomenologyresearch.pdf.

Looyeh, Majid Yoosefi., Kamali, Khosrow., Ghasemi, Amin., \& Tonawanik, Phuangphet. (2014). Treating Social Phobia in Children through Group Narrative Therapy. Journal the Art in Psychotherapy, 41(1), 16-20. https://doi.org/ 10.1016/j.aip.2013.11.005

McCroskey, J. C. (1970). Measures of communication-bound anxiety. Speech Monographs, 37, 269-277.

McLeod, John \& Balamoutsou, Sophia. (2007). Representing Narrative Process in Theray: Qualitative Analysis of a Single Case.Journal of Counseling Psychological Quarterly, 9(1), 61-67. http://dx.doi.org/10.1080/0951507 9608256353 
McLeod, John. (2007). The Emerging Narrative Approach to Counselling and Psychotherapy. British Journal of Guidance and Counseling, 24(2), 173-184. http://dx.doi.org/10.1080/03069889608260407

Murdock, Nancy L. (2009). Theories of Counseling and Psychotherapy: A Case Approach. England: Pearson Education Limited

Pribyl, B Cahrles., Keaten, James., \& Sakamoto, Masahiro. (2001). The Effectiveness of A Skills Based Program in Reducing Public Speaking Anxiety. Japanese of Psychological Research, 43(3): 143-155. http://doi.org/10.1111/1468-5884.t01-1-00171

Schultz L.T \& Heimberg R.G. (2008). Attentional Focus in Social Anxiety Disorder: Potential for Interactive Processes. Clinical Psychology Review, 28(7):12061221. http://doi.org/10.1016/j.cpr.2008.04.003

Shoai, Shirin. (2014). Instructor's Manual for Clinical Interviewing: Intake, Assessment, and Therapeutic Alliance. Canada: Psychotherapy.net, LLC

Siliman, B. (2009). Youth Views of Experiences and Benefits of Public Speaking. Journal of Youth Development, Bridging Research and Practice, 4(2); 88-97

Swenson, Angela. (2011). You Make My Heart Beat Fast: A Quantitative Study of The Relationship Between Instructor Immediacy, Classroom Community, and Public Speaking Anxiety. Journal of Undergraduate Research XIV, 1-12

Vasquez, Rosemary. (2000). Interviewing Children. Retrieved from http://www.casanet.org/library/advocacy/ interviewing.htm

Zell, E Warriner, A. B. \& Albarracin, D. 2012. Splitting of The Mind: When the You I Talk to is me and Needs Command. Social Psychological and Personality Science, $\quad 3(5)$ : 549-555. http://doi.org/10.1177/1948550611430164 